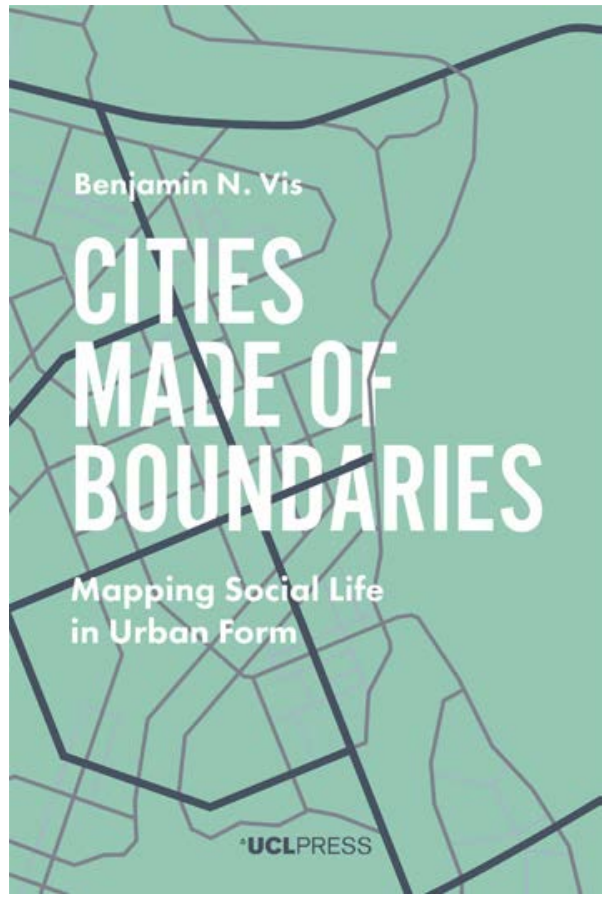

BENJAMIN N. VIS

\section{Cities Made of Boundaries. Mapping Social Life in Urban Form}

Londres: UCL Press, 2018, 416 págs. Encuadernación en rústica. Idioma: inglés. PDF de acceso abierto.

ISBN: 978-1-78735-105-9

DOI:https://doi.org/10.14324/111.9781787351059

\section{SERGIO GARCÍA-PÉREZ}

\section{Universidad de Zaragoza}

sgarciap@unizar.es

En un número de la revista ZARCH dedicado a explorar la idea espacial del límite con la pretensión de superar las visiones más convencionales, merece la pena dedicar un espacio a reconocer el trabajo que Benjamin N. Vis presenta en su libro Cities Made of Boundaries. Esta publicación presenta una novedosa aproximación al concepto de límite, ya que propone un análisis en profundidad de cómo el estudio de distintos tipos de límite puede contribuir a enriquecer el análisis urbano. Además de emplear la cartografía del límite como un mecanismo de análisis de la forma urbana, Cities Made of Boundaries propone algunas estrategias que contienen un gran potencial para convertirse en herramienta de proyecto.

El libro es resultado de una investigación desarrollada durante la tesis doctoral del autor en la Universidad de Leeds. Tesis que, curiosamente, comenzó a desarrollar sobre una temática diversa: el estudio de la ciudad Maya, evaluada a través de la lente contemporánea de la geografía urbana. Aunque a priori el giro puede parecer sorprendente, a recorrer las páginas del libro uno comprende - como ocurre en tantas otras ocasiones- la importancia que entraña conocer el recorrido y las etapas por las que ha pasado un trabajo de investigación para entender mejor el resultado. Probablemente, Vis no habría podido extraer gran parte de las conclusiones de su investigación, si no hubiera sido por su trabajo previo como arqueólogo en la cultura y civilización Maya.

Aunque, como él mismo reconoce, su encuentro e interés por la forma urbana haya llegado a posteriori, su investigación toma como punto de partida la limitación que comportan los métodos actuales de análisis urbano, que se encuentran condicionados por el contexto en el que se formulan. Según el autor, esta sobre-aproximación desde los entornos occidentales y globalizados provoca una 'miopía' temporal y contextual que impide reconocer otras formas urbanas menos 'comunes'. ¿Es posible estudiar la vida social de la forma urbana a través de métodos no condicionados por el contexto? Para Vis, si nos alejamos de la mirada dominante, podremos reconocer nuevos caminos que ayuden a responder a esa pregunta. Por eso, su investigación plantea una aproximación radical -aunque no en solitario- al estudio de la forma urbana.

Y es aquí donde Vis nos propone el estudio del límite como mecanismo para analizar la relación entre vida social y forma urbana en diversos contextos culturales y temporales. Para ello, el autor debe asumir la complejidad de un término como el de 'límite', y lo hace revisando la significación del concepto en disciplinas como la geografía humana, la sociología o la filosofía. A pesar de lo escurridizo del término, para él el límite es el "resultado de los requisitos intelectuales y experienciales de diferenciación que permiten que el proceso de habitabilidad del mundo tenga lugar" (p. 99). Como vemos, su noción de límite está relacionada con la realidad socio-espacial, al vincularse tanto al entorno construido como al hecho de habitar.

Un tema de investigación tan disruptivo requiere de un planteamiento canónico que permita caminar sobre seguro. Así, el libro se estructura en torno a tres grandes partes: la construcción de un marco teórico, el desarrollo de un marco metodológico y, por último, la aplicación de la metodología de análisis propuesta. Además de conferir solidez al discurso, esta estructura permite una lectura más flexible, aumentando en consecuencia el número potencial de lectores al que podría interesar esta investigación. Una flexibilidad que, dicho sea de paso, no va acompañada de la esperada facilidad de lectura. El texto, por el contrario, requiere un esfuerzo considerable por parte del lector.

Los lectores interesados en el marco teórico, capítulos 1 y 2, encontrarán las respuestas del autor a preguntas como: ¿en qué medida el entorno construido y habitado puede utilizarse en las investigaciones sociales, desde una perspectiva comparada? ¿Cómo podría diseñarse un método de investigación adecuado? ¿Cuál es el marco teórico que lo respalda?
En la transición entre el marco teórico y el desarrollo del marco metodológico, capítulos 3 , 4 y 5 , el autor responde a la cuestión acerca de qué información es clave para caracterizar y explicar el proceso humano de habitar el mundo. Como ya hemos dicho, la principal aportación del libro es el hallazgo del límite como estructura espacial capaz de responder a su hipótesis. Vis propone una sistematización del límite, una nueva ontología que, a partir de 14 categorías, permita reconocer la capacidad de relación social e interacción de la forma construida.

En la última parte del libro, capítulos 6 a 9 , Vis reflexiona sobre la aplicabilidad del método, mostrando, en primer lugar, algunos ejemplos situados en dos contextos diversos: Winchester y Chunchucmil. Este ejercicio es valioso, no solo para demostrar la validez de su investigación, sino también porque hace un esfuerzo por acortar la habitual distancia entre teoría y práctica del análisis urbano. A continuación, el libro discute la operatividad actual del método y sus mecanismos de cartografiado, sin olvidar las limitaciones inherentes a su aplicación. Estas reflexiones básicas -aunque en ocasiones poco frecuentesson de gran valor, ya que dejan una puerta abierta a nuevas miradas sobre su trabajo.

En mi opinión, la principal virtud de este libro es su planteamiento, que, utilizando la terminología científica, podría calificarse como investigación básica. La aplicación del análisis urbano a través del concepto de límite no parece hoy una tarea sencilla, ni tampoco rápida. Sin embargo, abre la puerta a futuras investigaciones interesadas en la búsqueda de métodos y aplicaciones, que podrán hacer uso del conocimiento que este libro aporta. Aunque quizá ahora sea difícil de imaginar, no debemos olvidar la velocidad con la que avanzan algunas técnicas como la foto-interpretación, los nuevos métodos de modelado terrestre digital, o muchos otros que aún no podemos ni siquiera intuir. Será el tiempo el que, finalmente, permita juzgar, el potencial de esta investigación, ya de por sí valiosa.

https://doi.org/10.26754/ojs_zarch/ zarch. 2020144525 